\title{
O DIREITO A CIDADES SUSTENTAVEIS COM APLICAÇÃO DO CONCEITO DE SMART CITIES: O USO DE NOVAS TECNOLOGIAS PARA A MELHORA DO MEIO AMBIENTE URBANO DE SÃO LUÍS DO MARANHÃO
}

\author{
Francisco Campos da Costa* \\ Gabriela Soldano Garcez**
}

\begin{abstract}
RESUMO: Na última centena de anos, o fluxo migratório do campo para a cidade e a célere urbanização dos centros urbanos transformaram a paisagem e o clima. Os centros urbanos mais asfaltados, menos permeáveis, mais quentes, pouco planejados e cuja pluviosidade natural é grande, são acometidos por episódios de inundação. São Luís não se difere desta realidade. Neste sentido, este artigo pretende abordar o desenvolvimento histórico das Smart Cities com sistemas anti-flood, e, eventuais tecnologias que podem ser adaptadas para São Luís do Maranhão. Ademais, serão abordados efeitos secundários relacionados a aplicação destas tecnologias e danos econômicos da sua não utilização.
\end{abstract}

PALAVRAS-CHAVE: Novas tecnologias; Smart Cities; São Luís - MA; Inundação; Direito Urbanístico.

\section{THE RIGHT TO SUSTAINABLE CITIES WITH THE APPLICATION OF THE SMART CITIES CONCEPT: THE USE OF NEW TECHNOLOGIES FOR THE IMPROVEMENT OF THE URBAN ENVIRONMENT OF SÃO LUÍS, AT MARANHÃO}

\begin{abstract}
In the last years, the migratory flow from the countryside to cities and the rapid urbanization of urban centers have transformed the landscape and climate. The more paved and less permeable, warmer, poorly planned urban centers with large natural rainfall are plagued by flood events. São Luís does not differ from this reality. This article intends to approach the historical development of the Smart Cities with anti-flood systems, and eventual technologies that can be adapted to São Luís, at Maranhão. In addition, it addresses side effects related to the application of these technologies and economic damages of their non-use.
\end{abstract}

KEY WORDS: New technologies; Smart Cities; São Luís - MA; Inundation; Urbanistic Law.

\footnotetext{
* Advogado. Pós graduado em Direito Marítimo e Portuário, pela Universidade Católica de Santos. Mestre em Direito Internacional (com bolsa CAPES), pela Universidade Católica de Santos. Doutorando em Direito Ambiental Internacional, pela Universidade Católica de Santos.

** Advogada e jornalista diplomada. Pós graduada em Direito Processual Civil e Direito Processual do Trabalho; Mestre em Direito Ambiental (com bolsa CAPES) e Doutora em Direito Ambiental Internacional (com bolsa CAPES), pela Universidade Católica de Santos. Conciliadora capacitada pela Escola Paulista de Magistratura. Professora de curso preparatório para a OAB e concursos públicos.
} 


\section{INTRODUÇÃO}

Historicamente, as cidades foram erguidas próximas ao mar, rios, lagoas e/ou lagunas para que os recursos hídricos e geográficos pudessem ser utilizados como ferramentas para o desenvolvimento socioeconômico.

São Luís do Maranhão ou Upaon-Açu (que significa “ilha grande”, em tupinambá), a única capital brasileira a ser fundada por franceses (MEIRELES, 1962, p. 136), também seguiu a tendência histórica de se localizar as margens de rios, mar, lagoas e lagunas. Geograficamente bem localizada, o porto de Itaqui tem um dos maiores calados naturais do mundo, de aproximadamente 23 metros, e uma das maiores variações de maré, de cerca de 7 a 8 metros.

Geograficamente, é um dos municípios que integra a Ilha de São Luís, composta por: São Luís, capital do Estado, Paço do Lumiar, São José de Ribamar e parte de Raposa. A capital maranhense possui baixadas alagadas e diversos manguezais que foram aterrados para que as malhas viárias fossem erguidas, bem como é formada por dunas que formam planícies litorâneas (MASSULO; SANTOS, 2014, p. 1-3).

A pluviosidade anual média ultrapassa que era de 2290 entre os anos de 1961-1990, segundo dados do INMET (2014). Entretanto, segundo ALVES (2016, p. 1-3) existe um mapeamento da mudança climática no Maranhão que apresenta resultados alarmantes, pois São Luís poderá ter sua temperatura aumentada em $3,1^{\circ} \mathrm{C}$ nos próximos 25 anos, enquanto o volume de chuva poderá cair $30,3 \%$ e o número de dias seguidos de chuvas deve aumentar $65,4 \%$.

Esta mudança climática, não impede que eventos extremos e inversos ocorram, ou seja, episódios de dias consecutivos de muita chuva, seguidos de dias totalmente sem chuva. Essa mudança se deve não apenas a mudanças climáticas, mas também relacionadas a urbanização da cidade, que tem perdido grande parte da flora natural.

São Luís apresenta assim, um conjunto perfeito para o caos urbano: urbanização sobre o solo que era adaptado para a recepção de grandes volumes de chuva mensalmente e hodiernamente se mostra incapaz de absorver tamanha precipitação; um sistema de esgotos planejados e modificados ao longo de décadas, mas cujas principais obras estão ultrapassadas, porque foram realizadas quando a malha urbana da cidade era menor, bem como tem planejamento, conceitos e cálculos que não se adequam a realidade hodierna da cidade.

Com as inovações tecnológicas e estruturais, especialmente após a segunda metade do século XX e início do século XXI, as cidades passaram a ter mais precisão nas aferições pluviométricas, bem como na integração e adaptação de tecnologias aplicadas ao meio ambiente 
urbano para mantê-lo resiliente, ou seja, capaz de se manter funcional apesar das fortes precipitações, permitindo o transito normal de seus habitantes e a realização de suas atividades.

Dessa forma, diante da evolução da uma sociedade plural e complexa, criam-se novas formas de conceber o relacionamento entre as pessoas e as cidades, em razão do aumento exponencial do número de indivíduos que procuram polos urbanos para moradia, trabalho e assistência médico hospitalar.

As inovações tecnológicas e estruturais, bem como suas implementações, são condições intrínsecas ao desenvolvimento da sociedade em simbiose com as cidades e os recursos naturais ao seu redor. Esta característica convencionou-se chamar de "Smart Cities", que buscam responder aos novos desafios globais através da evolução multidimensional, otimizando as cidades para dar eficiência no uso dos recursos e serviços disponíveis à população.

Entretanto, para a efetiva criação destas cidades são necessárias medidas basilares integradas para a elaboração de planos de governança que envolvam os mais diversos setores, como ONG's, parcerias público-privadas, eventuais transferências de tecnologias, incentivos governamentais, tanto jurídicos quanto econômicos, visando a criação e efetivação de políticas públicas voltadas a proteção e defesa do meio ambiente saudável e ecologicamente equilibrado.

Neste sentido, o presente artigo tem como principal questão: quais medidas de gestão e quais são as tecnologias podem ser aplicadas a São Luís do Maranhão para torná-la uma Smart City com um sistema efetivo de anti-flood e/ou mitigar os danos decorrentes de inundações?

Destarte, será analisado, primeiramente, o desenvolvimento histórico das "Smarts Cities" com sistemas anti-flood, indicando sua viabilidade e os custos da implementação de tecnologias economicamente sustentáveis para a manutenção da vida e segurança da população que vivem em cidades que são usualmente acometidas por inundações e/ou enchentes.

As principais tecnologias apresentadas neste artigo serão: pavimentação drenante, tendo como principal exemplo o asfalto permeável ou poroso e o Flood Awereness System (FAS), adaptado a realizada ludoviscense.

As análises do presente artigo não se limitarão apenas a apresentar as tecnologias, mas também seus custos de implementação e adaptação a cidade de São Luís, considerando suas possibilidades econômicas e os eventos climáticos que lhe atingem. Ademais, serão discutidos possíveis benefícios secundários para as tecnologias mencionadas. 


\section{DiReito A CIDAde SUSTENTÁVEL: O CAMINHO A PERCORRER PARA O ACESSO AO MEIO AMBIENTE URBANO ADEQUADO}

O avanço da concretização de um futuro baseado no sistema de desenvolvimento sustentável (conforme proposto pela Agenda 21 e sustentado pela Agenda 2030) somente será possível mediante esta conscientização da importância de defesa e proteção do meio ambiente, capaz de formar "agentes de mudança" comprometidos com melhores práticas ambientais, despertando os atores sociais a fazer uso de todos os instrumentos de proteção e defesa disponíveis para este direito indisponível.

O Brasil já possui legislação suficientemente abrangente para tal desiderato, o que se necessita é da efetivação de tais princípios.

A busca por melhores condições do ordenamento do ambiente urbano garante qualidade de vida à população, através da realização de "cidades sustentáveis", que visam, por exemplo, criação de "espaços verdes" (como parques ou praças para utilização da população), melhora da mobilidade urbana (ações que proporcionem a diminuição dos gases do efeito estufa, para o combate ao aquecimento global), o uso adequado da infraestrutura urbana, planejamento de transporte público ou incentivo ao uso de transportes alternativos (como as bicicletas), o descarte de resíduos sólidos e a reciclagem (até mesmo com o incentivo à criação de cooperativas), o gerenciamento do solo, a economia de água e energia, a diminuição da poluição, utilização de materiais renováveis e/ou recicláveis, instalação de empreendimentos e/ou edificação adequadas (com, por exemplo, programas de reuso de água), atividades voltadas à educação ambiental (que incentivam o consumo consciente), entre outros elementos de políticas públicas que contribuem para a sustentabilidade ambiental.

Tal configuração urbana ideal não é possível sem a participação eficiente e efetiva da sociedade neste processo, vez que a Constituição Federal de 1988 determina que é responsabilidade tanto do Poder Público quanto da coletividade o respeito e a preservação do meio ambiente para as presentes e futuras gerações, para que haja a possibilidade do oferecimento de ferramentas visando a sensibilização e a mobilização rumo a cidades brasileiras mais econômica, social e ambientalmente sustentáveis.

Neste sentido, o Estatuto da Cidade exige a gestão democrática dos espaços urbanos, através da participação da população tanto na elaboração dos Planos Diretores quanto na fiscalização da implementação de seus mecanismos, por meio de (artigo 40):

Rev. de Direito Urbanístico, Cidade e Alteridade | e-ISSN: 2525-989X | Maranhão | v. 3 | n. 2 | p. 1-17 | Jul/Dez. 2017. 
I - a promoção de audiências públicas e debates com a participação da população e de associações representativas dos vários segmentos da comunidade;

II - a publicidade quanto aos documentos e informações produzidos;

III $-\mathrm{o}$ acesso de qualquer interessado aos documentos e informações produzidos.

A promoção de ações efetivas depende da pressão popular tanto sobre empresas privadas, poder público quanto sobre a mídia, sejam os meios de comunicação mais tradicionais, seja por redes sociais. Denúncias ao Ministério Público, denúncias ao Tribunal de Contas, participação da população na Assembleia Legislativa são ação práticas capazes de mover ações do poder público e incentivá-lo a fazer parcerias público-privadas, especialmente quando demonstrado os ganhamos econômicos e sociais de se ter uma cidade resiliente, que não interrompe seu fluxo natural em decorrência de inundações, afinal, o foco é repensar a cidade para que suas estruturas não inundem e impeçam o fluxo natural de pessoas e a continuidade da prestação de serviços.

\subsection{Criação conceitual e evolução histórica das Smart Cities}

O modelo urbano adotado por uma cidade tem de adaptar-se as necessidades da população, em razão das modificações e da dinamização exigida por estes em relação ao ambiente em que vivem e convivem, que demonstra através dos anos estar em crescente atualização.

O critério para avaliar se determinada área pode ser considerada urbana, trata-se da combinação de elementos imprescindíveis para uma cidade, como, por exemplo, a densidade geográfica, a presença de infraestrutura básica (como energia elétrica, água encanada, esgoto e transporte público) e concentração da atividade econômica, além de serviços indispensáveis, como educação e saúde (UNITED NATIONS, 2014, p. 8).

Segundo relatório da Organização das Nações Unidas (ONU), denominado “2014 Revision of World Urbanization Prospects", o planeta passou por um rápido processo de urbanização nas últimas seis décadas. Atualmente, $54 \%$ da população mundial vive em áreas urbanas, o que já representa a maioria dos cidadãos, tendo em vista que em 1950 apenas 30\% da população era urbana. Tal proporção aumentará para 66\% até o ano de 2050, o que fará com quem mais de 2,5 milhões de pessoas passem a viver em áreas denominadas urbanizadas (UNITED NATIONS, 2014, p. 5). 
Do incremento populacional decorre a ampliação do espaço urbano e o surgimento de problemas característicos, como, por exemplo, congestionamento, desemprego, violência urbana, poluição, mudanças climáticas, industrialização, falta de espaço territorial para abrigar novos moradores, criação de assentamentos irregulares, desperdício de água, mal uso de efluentes, despejo de resíduos sólidos, enchentes, entre outros.

Esta realidade exige a adoção de uma nova sistemática nas cidades, através de um planejamento urbano adequado que represente e incremente a produtividade, a qualificação e a identidade das cidades, consideradas como "organismos vivos", mantendo o coração pulsante, revitalizando pontos enfraquecidos e criando novos estímulos, o que é necessário para a manutenção da eficiência da cidade através do fornecimento de serviços urbanos adequados, além de conferir qualidade de vida e meio ambiente para seus habitantes.

Assim, é necessária a criação e o desenvolvimento de infraestrutura e de políticas públicas que permitam tal crescimento sem implicar na diminuição dos benefícios que viver na cidade pode representar, incluindo-se o desenvolvimento sustentável.

Neste sentido, a urbanização sustentável requer que as cidades tenham a capacidade de gerar empregos e expandir a infraestrutura básica, ao mesmo tempo em que garantem igualdade ao acesso destes serviços e recursos, reduzem o número de habitantes que não possuem moradia digna, bem como preserva os recursos naturais disponíveis e finitos.

\footnotetext{
The process of urbanization historically has been associated with other important economic and social transformations, which have brought greater geographic mobility, lower fertility, longer life expectancy and population ageing. Cities are important drivers of development and poverty reduction in both urban and rural areas, as they concentrate much of the national economic activity, government, commerce and transportation, and provide crucial links with rural areas, between cities, and across international borders. Urban living is often associated with higher levels of literacy and education, better health, greater access to social services, and enhanced opportunities for cultural and political participation (UNITED NATIONS, 2014, p. 7).
}

Resta claro, portanto, a necessidade de gestão adequada da cidade e da expansão urbana com o uso adequado das tecnologias disponíveis.

Nesta sistemática moderna ganha espaço a premissa adotada pelas denominadas Smart Cities, que procuram conceber um modelo de sustentabilidade urbana, aliada as novas possibilidades proporcionadas pela conectividade e tecnologias (da informação e comunicação - TIC, além do fluxo de dados), implementando esse novo conceito em relação às cidades 
tradicionais (com a devida adaptação da eficiência com os recursos escassos disponíveis, sejam ambientais, financeiros ou de pessoal capacitado).

É a cidade que quebra os paradigmas do Planejamento Urbano Convencional, consistindo em um ambiente de inovação e integração de sistemas voltado para a eficiência urbana e construído dinamicamente com a participação ativa de usuários e instituições, por meio da aplicação da TIC (PRADO, 2014, p. 34).

Isso ocorre porque, a urbanização deve estar plenamente vinculada aos três pilares clássicos do desenvolvimento sustentável: desenvolvimento econômico, social e ambiental, com a promoção de inclusão, equidade e bem estar para quem vive na urbe.

Dessa forma, uma Smart City alia corretamente sociedade, planejamento urbano, administração pública e uso de tecnologias disponíveis, formando uma infraestrutura inteligente a disposição da população, conectando, portanto, as diversas esferas que compõem uma cidade.

A Real Smart City is emerging as a structured organic whole, single urban entity, completeness, totality, and integral unity of is parts, components, constituents, as a technologically, socially, and economically integrated/connected urban eco system (ABDOULLAEV, 2001, p. 4).

Trata-se, portanto, de uma cidade que possui pleno desenvolvimento urbano, auxiliado e promovido pelas tecnologias, que, neste sentido, torna-se agente efetivo de transformação da cidade, de acordo com as necessidades apresentadas.

As Smart Cities fazem uso de TIC, bem como dos dados disponíveis, para alcançarem a condição de mais inteligentes e eficientes no uso de recursos, o que resulta em uma redução de custos, economia energética, aperfeiçoamento de serviços, melhora na qualidade de vida e contenção da pegada ambiental. Trata-se de um ambiente urbano que funciona (PRADO, 2014, p. 30).

Este entendimento (de procurar solucionar problemas reais, transformando cidades) deve ser utilizado, por exemplo, em locais que sofrem com episódios de enchentes, objeto de estudo específico deste trabalho, através da implantação de sistemas denominados anti-flood (ou anti-flooding), que melhoram a qualidade ambiental das cidades e de seus habitantes.

É inevitável que, uma vez alcançado este estágio chamado Smart City, a saúde ambiental venha como consequência. Isto pode ser afirmado porque, em uma comunidade cuja organização atende ao nível de eficiência proposto, os recursos são, obrigatoriamente, melhor utilizados (PRADO, 2014, p. 33). 


\section{EXEMPLOS DE SMART CITIES COM SISTEMAS ANTI-FLOOD}

Em tradução livre, sistema anti-flood é aquele que permite a aplicação de tecnologias que impedem e/ou dificultam enchentes ou inundações (flood, em inglês).

A fim de demonstrar a utilização deste sistema, dentre as lugares pelo mundo que adotam tais tecnologias, serão utilizados exemplos complexos e com modelos socioeconômicos diferentes entre si.

Tóquio, a metrópole japonesa de milhões de habitantes, preveniu-se das enchentes com o investimento de bilhões de reais, através da construção de gigantes reservatórios de água a 40 metros da superfície. Há um monitoramento dos leitos dos rios para que, com o alcance de determinado nível, a água excedente seja escoada para os reservatórios construídos (cinco tanques com quilômetros de comprimento, interligados por túneis). Este trabalho de escoamento é realizado pelos bueiros da cidade, que, por esta razão, não podem estar obstruídos. Assim, para que os reservatórios funcionem perfeitamente, a população deve colaborar e, não jogar lixo nas ruas. Com isso, a última enchente em Tóquio ocorreu em 2005, um ano antes de o sistema entrar em pleno funcionamento.

Algumas cidades dos Estados Unidos (como New Jersey ou Denver/Colorado) já utilizam a técnica denominada "asfalto (ou pavimento) poroso", principalmente em estacionamento de veículos, pátios, playgrounds, entre outros locais. Trata-se de asfalto ou concreto que permite que a drenagem das águas da chuva que caem no local, impedindo poças e acumulo indesejado de água, o que, consequentemente, aumenta a segurança (diminuindo, por exemplo, eventuais aquaplanagens) e o conforto da população (pois, além de tais benefícios, o asfalto poroso também diminui o barulho produzido pelos veículos, reduzindo, portanto, a poluição sonora).

Percebe-se, portanto, que podem ser empregadas diversas tecnologias para o emprego de técnicas dos mais diferentes estilos com a finalidade de criação e utilização de uma espécie de sistema anti-flood.

Rev. de Direito Urbanístico, Cidade e Alteridade | e-ISSN: 2525-989X | Maranhão | v. 3 | n. 2 | p. 1 - 17 | Jul/Dez. 2017. 


\section{INOVAÇÕES TECNOLÓGICAS PARA CIDADES QUE SOFREM COM INUNDAÇÕES}

As tecnologias utilizadas para a contenção de inundações em cidades não é nova, afinal, desde a Mesopotâmia antiga já existiam construções para impedir inundações decorrentes do aumento do nível dos rios pelas chuvas, de modo que a barragem mais antiga do mundo data de 3.000 anos a. C.

Desde aquela época, tais construções já possuíam múltiplas funções, além da tentativa de supressão de inundações decorrentes do aumento do nível dos rios que cruzavam as cidades ou que as margeava. Outras funções derivavam do represamento de água, que representavam importante fonte de irrigação e abastecimento para consumo humano.

A evolução técnica da engenharia teve outros pontos críticos e, que significaram transformações importantes para as cidades. O planejamento estratégico de construções romanas após o $2^{\circ}$ século D.C. que empregavam a utilização de argamassa a prova d'água permitiram obras com dimensões maiores, cuja vida útil era distinta das demais.

A Holanda é um exemplo de cidade cuja existência e desenvolvimento é intrinsecamente ligada a fontes hídricas, afinal, trata-se de um país que está pouco acima do nível do mar e é cortado por diversos rios, ou seja, sempre teve sua existência ameaçada pelas intempéries naturais.

A capital da Holanda, Amsterdam, foi erguida nas redondezas da barragem do rio Amstel. Seu antigo nome "Amstelredam" é referência ao nome do rio e da barragem, em inglês "dam". Essa mesma analogia se aplica a Rotterdam, cuja barragem foi erguida nas proximidades do rio Rotte.

A evolução deste tipo de tecnologia juntamente com a evolução da ciência e das necessidades dos habitantes das cidades mudou drasticamente a engenharia e as funções das represas e suas barragens, afinal, a tecnologia acompanha intrinsecamente os novos conceitos sobre uso de espaço e função social.

Hodiernamente, em virtude do aumento populacional em áreas urbanas, bem como a urbanização das cidades e seu natural processo de impermeabilização, a diminuição das áreas verdes e a alteração no ciclo hidrológico, nos grandes centros urbanos, as chances de inundação aumentam em 6 a 7 vezes (TUCCI, 2005, p. 91). 
Diante destes dados e do fato de existirem apenas na América Latina pelo menos 44 cidades com população superior a 1 milhão de habitantes e, pelo menos 388 em escala global, existem ainda 16 mega-cidades, cuja população supera os 10 milhões de habitantes, segundo dados das Nações Unidas de 2003 (TUCCI, 2005, p. 9).

É necessário repensar as tecnologias utilizadas, afinal, já não se trata apenas de controle de inundação provocada pela cheia dos rios que margeavam as cidades, mas pela inundações de várias vias que impede a livre circulação de pessoas e transporte de mercadorias, ocasionando perda de tempo, estresse na população e perda de receita pela impossibilidade de fluxo natural de consumo em decorrência do tempo perdido.

\subsection{Pavimentação Drenante}

O asfalto poroso não apenas fornece uma superfície de pavimento forte para estacionamento, calçadas, trilhas e estradas, mas também são projetados para gerenciar e tratar o escoamento de águas pluviais. Com o devido design e instalação, pavimentos de asfalto poroso podem fornecer uma solução de custo eficaz para a gestão de águas pluviais de forma eco-eficiente, especialmente porque melhora a transferência de oxigênio para as raízes de árvores e vegetais próximos (WINSCONSIN ASPHALT PAVEMENT ASSOCIATION, 2015, p. 1-2)

Dentre os principais benefícios da utilização do asfalto poroso, segundo WINSCONSIN ASPHALT PAVEMENT ASSOCIATION (2015, p. 2), pode-se enumerar: a redução do ruído dos pneus e motores, recarga dos lençóis freáticos (uma vez que a água absorvida se infiltrará nas camadas mais profundas do solo, seja pelo degelo da neve, seja pela água pluvial), bem como a redução da contaminação no escoamento da água e carregamento de sendimentos.

Ademais, considera-se que essa tecnologia tem baixo custo de desenvolvimento e sua implementação reduz a necessidade de estruturas drenantes (WINSCONSIN ASPHALT PAVEMENT ASSOCIATION, 2015, p. 2). Por fim, sua implementação concede créditos em sistemas de classificação de construção verdes, como Liderança em Energia e Design Ambiental, Rodovias Verdes "Greenroads" e o Código Verde Internacional de Construção (WINSCONSIN ASPHALT PAVEMENT ASSOCIATION, 2015, p. 2).

A implementação em rodovias tem como principais benefícios: a redução de ruídos, e, o aumento do atrito do pneu com o solo em pista molhada. Ademais, considera-se que o asfalto 
poroso ainda é responsável pela redução da temperatura do asfalto, ou seja, uma tecnologia resfriante que ocorre pela existência de vazios de ar que existem na própria estrutura. Destarte, o asfalto poroso pode amenizar o efeito de ilha de calor, extremamente comum em cidadesglobais, especialmente as localizadas em climas tropicais.

Para o Brasil, em especial para o estado de São Paulo, essa tecnologia tem o potencial de reduzir a quantidade de acidentes nas estrada, pois evitaria acúmulo de água, bem como melhora a visibilidade em pista molhada e o aumento do atrito com o asfalto (WINSCONSIN ASPHALT PAVEMENT ASSOCIATION, 2015, p. 2).

\subsection{Sistema de Alerta de Inundação}

O Sistema Europeu de Alerta de Inundação, European Flood Awareness System (EFAS) é o primeiro sistema de monitoramento e previsão de inundações da Europa. Sua principal função é de alertar os serviços nacionais e regionais hidrológicos, bem como o Centro de Coordenação e Reação Europeu (ERCC), para possíveis episódios de inundação com 10 dias de antecedência.

No modelo europeu centrais distintas localizadas em áreas distintas são responsáveis por medição diária e permanente de dados como aumento ou redução do nível do mar, movimentações meteorológicas e sísmicas, compartilhando dados e dando o melhor resultado possível no menor intervalo de espaço, permitindo evacuação da população em curto período de tempo.

Comparativamente, seria o equivalente a alertar a Defesa Civil e Corpo de Bombeiros para a devida verificação em loco das possíveis necessidades de evacuação da população e isolamento da área. Entretanto, adotando pontos de aviso e movimentação rápida da Defesa Civil dentro da cidade afim de evitar acumulo de carros e pessoas em áreas que provavelmente serão inundadas, evita perdas e danos significativos.

\subsection{Pavimento "frio" ou Asfalto "verde"(Cool Pavment/ Green asphalt)}

Apesar de se tratar de tecnologias distintas, são semelhantes. A ideia base dessas tecnologias é modificar os componentes ou mesmo a matéria prima do asfalto para que sua coloração final seja distinta do tom preto padrão. A diferença é que o concreto utilizado ou 
outros materiais utilizados na composição desta pavimentação deve refletir progressivamente menos luz do Sol do que os atuais 50\% refletidos pelo asfalto padrão utilizado hodiernamente.

O estudo produzido pelo Berkeley Lab (2017, p.1), aponta ainda impactos positivos, tais como: Economia de energia e redução de emissões; Melhor conforto e saúde (menos calor, estresse, queimadura de pele, câncer de pele, etc.);, dentre outros benefícios.

\subsection{Bueiro Inteligente}

Utilizado atualmente na cidade de São Paulo, ainda em caráter experimental, essa tecnologia se baseia numa espécie de caixa colocada dentro do bueiro que serve se peneira e pode ser facilmente removida para que o fluxo de agua seja continuado nos bueiros e flua pelas galerias.

É valido ressaltar que sensores posicionados dentro dessa peneira em formato de caixa alertam sobre o momento necessário de ir esvaziá-la, portanto evitando que a sua utilização acabe por perder o significado.

\subsection{Viabilidade e custos de implementação de tecnologias sustentáveis}

Segundo dados do Swiss Reinsurance, a população brasileira exposta às inundações possivelmente aumentará de 33 milhões em 2011 para 43 milhões em 2030. A expectativa anual de perdas estavam estimadas em U\$D 1.4 bilhões de dólares em 2011, devendo subir para U\$D 4 bilhões de dólares em 2030 (SWISSRE, 2011a, p.2). Essa estimativa inclui tanto áreas urbanas quanto áreas não urbanas. Entretanto, 40\% dessa população localiza-se no sudeste do Brasil, e, segundo dados, 1.5 milhões de pessoas estão sob risco de inundações decorrentes de enchentes de rios e inundações decorrentes de precipitação, apenas na região metropolitana (SWISSRE, 2011a, p.7)

Em 2004, inundações mais significativas, atingiram 15 estados entre o norte e o sudoeste do Brasil, atingindo a produção agrícola e dando um prejuízo de aproximadamente U\$D 303 milhões de dólares. Ademais, em Janeiro de 2011, inundações em São Paulo e no Rio de Janeiro, mataram 800 pessoas e desabrigaram mais de 10.000 (SWISSR, 2011b, p. 2).

Por fim, se ainda restarem dúvidas sobre a necessidade e viabilidade econômica ao fazer um balanço entre os prejuízos já ocorridos e os vindouros, observa-se ainda um último 
dado alarmante, o aumento nos episódios de inundação no Brasil subiram de 20 entre 1990 a 1999, para 34 entre 2000 e 2009.

São Luís do Maranhão pode se beneficiar das práticas supramencionadas da seguinte forma: A educação ostensiva, nas escolas, auto escolas, bem como fiscalização nas ruas e multas severas pelo ato de jogar lixo na rua criaria um fator de impacto positivo para a redução do acumulo de lixo nas galerias que muitas vezes leva as inundações. Como São Luís não tem um fluxo de capital suficiente para criar estruturas drenantes tão grandes como a japonesa, que aprenda com a experiência daquela a educação popular para reduzir os danos decorrentes de um péssimo habito: jogar lixo na rua.

Uma tecnologia que pode ser desenvolvida pela Universidade Federal juntamente como iniciativa público privada é o asfalto poroso frio. Ou seja, uma mistura de tecnologia entre asfalto poroso e o asfalto frio, em que a combinação de materiais permitirá que as águas pluviais fossem parcialmente absorvidas e filtradas pelo asfalto para que não chegassem ao solo e ao subsolo contaminadas, tivessem condições de retornar ao lençol freático sem poluentes e ajudando assim no ciclo hidrológico na capital.

Outrossim, com a utilização do asfalto frio, a redução da ilha de calor, o mal estar dos motoristas, passageiro, bem como a redução com custo de resfriamento, ocasionaria uma redução do consumo de energia, uma redução na procura por hospitais público por pessoas que sofrem com o calor e uma melhoria na qualidade de vida e fluxo de pessoas pela cidade.

Com as estações de alertas nas principais áreas de inundação da cidade, é possível que se evite acidentes, seja com o policiamento em áreas cujos motoristas costumam dirigir com maior velocidade, seja em áreas sujeitas a inundação em que a população corre risco de vida e a ação pode e deve ser rápida tanto dos bombeiros quanto da defesa civil.

Por fim, mas não menos importante, uma ação conjunta entre a manutenção dos bueiros, bem como a ampliação dos mesmo para serem capazes de aguentar a vazão de chuvas com precipitação extremas, o que, conforme já foi dito, tende a ocorrer com mais frequência nos próximos anos. A segunda ação decorre da instalação, monitoramento e manutenção dos bueiros inteligentes para que caso a população ainda não esteja devidamente educada, a administração pública ainda seja capaz de evitar danos ao fluxo normal da cidade.

A gestão democrática dos espaços urbanos permeia questões relativas à acessibilidade integral de todos os munícipes e de visitantes. Para que haja gestão efetiva é necessário que haja participação e ação. 
Quanto à participação popular, as denúncias feitas pelos munícipes, bem como a utilização de gadget (dispositivos eletrônicos portáteis) que tem capacidade de interação integrada entre seus usuários para que haja informação em tempo real sobre as ações realizadas sobre o local denunciado ou mesmo pela congregação de ideias e efetiva gestão do espaço causador de problemas.

De forma prática, canais de ouvidoria de órgãos públicos sendo contatados para que realizem ações devem ser utilizados, bem como deve haver cobranças e fiscalização continua por parte da população. Dentre as possibilidades de aparelhos portáteis, fotografias, vídeos, e aplicativos que indiquem em tempo real condições climáticas, fluxo de automóveis e precipitação media naquela área devem compor bancos de dados para que sejam analisados tanto pelo poder público, quanto pelas universidades, quanto pelas empresas.

A análise de dados em multinivel e capaz de criar pressões para a consecução de objetivos distintos de pessoas físicas, jurídicas e organizações com interesses diversos. Em termos práticos o munícipe acometido por inundações próximas a sua residência tem como principal(is) motivação(ões) questões relacionadas a locomoção, trabalho e saúde, seja mental ou física.

Já as empresas tem problemas logísticos (receber e enviar mercadorias, etc) e perdas significativas de caixa, seja porque o clientes não conseguem se locomover até a loja, seja porque o clientes acabam perdendo interesse de fazê-lo por questoes de intrafegabilidade. Outrossim, é importante mencionar que dados seguros quanto aos custos de implementação e funcionamento de empresas atraem investimentos pelo conhecimento efetivo do mercado. $\mathrm{O}$ desconhecimento destes dados bem como a incerteza sobre investimento na cidade pode inviabilizar ou mesmo perder a confiança de empresários dispostos a

As universidades, como principais centros de captação e difusão de informações, deve ser capaz de captar esses grandes dados (big data) e utilizá-lo como banco de dados para acesso por munícipes, empresas e setor público.

Este último deve compreender que a falta de planejamento e ação levam a perdas econômicas severas, tais como: aumento de estress no transito e consequente aumento de acidentes, bem como doenças relacionadas a este. A impossibilidade de trafegar nas vias em velocidade média razoável ou mesmo no caso de ficar parado no transito em vez de produzir riquezas, influi diretamente na arrecadação de imposto e circulação de riquezas e cria um efeito bola de neve para toda a população da cidade.

or razoes distintas para fins distintos. 
Por outro lado, para que essa participação seja eficiente, é necessário que a população tenha subsídios educacionais, tecnológicos e informacionais, o que dará embasamento de qualidade para a aplicação prática das questões que necessitem do conhecimento da sociedade imprescindíveis para a implementação, execução e fiscalização de políticas públicas voltadas à proteção e defesa do meio ambiente.

Tais subsídios educacionais e tecnológicos se formam especialmente através de parcerias entre setores públicos e privados, levando-se em consideração a alteridade (ou seja, as diferenças) entre as parcelas da população que terão acesso a essa informação de qualidade, ao mesmo tempo em que atuarão todos juntos em prol do meio ambiente ecologicamente equilibrado.

A aplicação prática dos conhecimentos e tecnologias apresentados neste texto, deve embasar ainda mais pesquisas sobre o assunto e servir de inspiração e ação para a instalação das mesmas a partir do binôminio possibilidade $\mathrm{x}$ necessidade. A necessidade já existe, entretanto, e necessário se fazer com o que essas possibilidades se tornem reais, exigindo dos órgãos competentes, cobrando do corpo político e vetorizando ideias entre a iniciativa privada e a administração pública.

\section{CONCLUSÃO}

A cidade de São Luís do Maranhão tem um dos maiores índices de pluviosidade do Brasil e seu planejamento, especialmente quando relativo a questões de proteção contra inundações e muito deficitário.

A atuação pratica dos munícipes cobrando do poder público, exigindo do corpo político, fiscalizando obras, denunciando o descaso da administração pública quanto ao efetivo cumprimento de obras para a melhoria da vida na cidade e consequentemente da qualidade de vida da população, deve impulsionar ações práticas destas pessoas.

Outrossim, denúncias ao Ministério Público, ao Tribunal de Contas e até mesmo a mídia, corrobora com a força popular em mover os seus governantes e as empresas para a criação de uma cidade mais plural e que segue os anseios de sua população.

A educação em todos os níveis, básica, média e superior e a atuação fática das Universidades, em especial a Federal e a Estadual, que contam com laboratórios que devem ser utilizados para criar e testar projetos de pesquisa que demonstrem tanto para o setor público 
quanto para o setor privado todas as perdas decorrentes da não ação conjunta. Esta, também deve ser medida para melhoria do meio ambiente urbano de São Luís do Maranhão.

As tecnologias mencionadas neste artigo: pavimentação drenante, pravimento frio, bueiro inteligente, sistema de alerta de inundação, educação socioambiental para evitar o acumulo de lixo jogado nas ruas são tecnologias que juntamente com redes sociais viabilizam a comunicação instantânea e alerta de forma rápida, pratica e com baixo custo.

\title{
REFERÊNCIAS BIBLIOGRÁFICAS
}

\begin{abstract}
ABDOUllaEV, Azamat. A Smart World: A Development Model for Intelligent Cities [The Trinity World of Trinity Cities]. EIS Encyclopedic Intelligent Systems/SMART GROUP, 2011. Disponível no site: <http://www.cs.ucy.ac.cy/CIT2011/files/SMARTWORLD.pdf>. Acesso em: 09 de março de 2016 .
\end{abstract}

ALVES, Reginaldo. Projeto Vulnerabilidade à Mudança do Clima. 8 novembro 2016. Disponível em: $<$ https://portal.fiocruz.br/pt-br/content/estudo-inedito-mapeia-mudanca-declima-no-maranhao>. Acesso em 20 de junho de 2017

PRADO, Kárys Cristina Diederichs; SANTOS, Patrícia Estevão dos. Smart Cities: Conceito, iniciativas e o cenário carioca. Rio de Janeiro: Universidade Federal do Rio de Janeiro/ Escola Politécnica, $2014 . \quad$ Disponível em: <http://monografias.poli.ufrj.br/monografias/monopoli10012947.pdf>. Acesso em: 07 de março de 2016.

MASULLO, Yata A. G.; SANTOS, José de R. C. Geoprocessamento aplicado a análise do avanço do processo de urbanização e seus impactos ambientais na ilha do maranhão. V Congresso Brasileiro de Gestão Ambiental. Belo Horizonte - MG , 2014.

MEIRELES, Mário Martins. França Equinocial, São Luís, Tipografia São José, 1962.

TUCCI, Carlos E. M. Gestão de Águas Pluviais Urbanas/ Carlos E. M.Tucci - Ministério das Cidades - Global Water Partnership - Wolrd Bank - Unesco 2005. Disponível em:< https://labgeologiaambiental.jatai.ufg.br/up/285/o/Gest\%C3\%A3o_de_Aguas_Pluviais_.PD F?1370615799> Acesso em 20 junho de 2017

UNITED NATIONS - DEPARTMENT OF ECONOMIC AND SOCIAL AFFAIRS. World Urbanization Prospects the 2014 Revision Highlights. New York: United Nations, 2014. Disponível no site: <http://esa.un.org/unpd/wup/Publications/Files/WUP2014Highlights.pdf>. Acesso em: 09 de março de 2016.

WINSCONSIN ASPHALT PAVEMENT ASSOCIATION. Porous Asphalt Pavements. Setembro 2015. Disponível em:< http://www.wispave.org/wpcontent/uploads/dlm_uploads/WAPA_Tech_Bulletin_Porous_Asphalt_Pavements_201509.pdf>. Acesso em 20 de junho de 2017. 


\section{Sites consultados:}

<http://www.pliniotomaz.com.br/downloads/capitulo60_pavimento_poroso.pdf>. Acesso em: 14 de março de 2016.

<http://floodlist.com/protection/g-cans-project-tokyo-flood-tunnel>. Acesso em: 26 de março de 2016.

<http://www.water-technology.net/projects/g-cans-project-tokyo-japan/\#top>. Acesso em: 25 de março de 2016.

<https://www.efas.eu/>. Acesso em: 25 de março de 2016.

https://view.officeapps.live.com/op/view.aspx?src=http://www.inmet.gov.br/webcdp/climatologia/ normais/imagens/normais/planilhas/Numero-Dias-Precipitacao-Maior-ou-Igual-1mm_NCB_19611990.xls Acesso em 20 de junho de 2017

http://g1.globo.com/ma/maranhao/noticia/2013/06/no-porto-do-itaqui-projeto-de-terminal-degraos-se-arrasta-ha-10-anos.html Acesso em 20 de junho de 2017

http://g1.globo.com/ma/maranhao/maranhao-natureza/noticia/variacao-de-mare-no-maranhao-euma-das-maiores-do-mundo.ghtml Acesso em 20 de junho de 2017

https://heatisland.Ibl.gov/coolscience/cool-pavements acesso em 20 de junho de 2017

http://www.administradores.com.br/artigos/negocios/um-bueiro-inteligente-para-compensarnossa-burrice/65572/ 